\title{
Study on Supervision Mechanism in Mobile Value-added Market Based on Stackelberg Game Theory
}

\author{
Di ZHAO \\ International School \\ Beijing University of Posts and Telecommunications \\ Beijing 102209, China \\ ee08b509@bupt.edu.cn \\ Chuanliang JIA \\ School of Management Science and Engineering, \\ Central University of Finance and Economics, \\ Beijing 100081, China \\ cljia@cufe.edu.cn
}

\begin{abstract}
- since powerful supervision on the mobile valueadded services is lacking nowadays, the mobile market goes into a tendency of being rather chaotic. This research will analyze the behavior of both the service providers and mobile operators, with game theory model to be established. Moreover, the Nash Equilibrium will also be considered which shows that the costs and extent of the mobile operator's supervision besides the penalty for the service provider's being caught will definitely influence the probability for service providers to violate the rules. On the other hand, the proportion of illegal gains shared by mobile operators and the penalty degree for service provider s may be the main factors that affect the mobile operator's supervision choices. At last suggestions are made on the service provider's strategic choices.
\end{abstract}

Index Terms-M obile value-added market; Supervision strategies; Game theory

\section{INTRODUCTION}

Recent years has seen a great tendency in an increasing number of mobile users, which correspondingly leads to the rapid development of the value-added mobile service in China dominated by Short Message Service. It's shown that the value-added mobile market in China in 2007 has approached to 120 billion Yuan compared with the market share of 94 billion in 2006, and further increased to 145 billion Yuan in 2008 partly due to the Olympic Games. Moreover in 2009, it has reached to 180 billion Yuan with an increasing rate of 23.5\%. During these amazing statistics, SMS, as a dominant leader, takes about $72 \%$ shares of the market, while services like WAP, feature rings only contribute $10 \%$ and $9.2 \%$ to the market. With the frequent updating speed of techniques and terminal products, besides the arrival of 3G's time, value-added mobile service in China will gradually move towards the diversified direction.

However, heated competition and veiled crisis are unexpectedly hidden behind the great market potential.
Although the scale for a value-added market, shared by the mobile operator and service provider together is expanding rapidly, they are not under strong supervision and administration. Moreover, served as both the designer of the market rules and the sharer of benefits, the mobile operator itself definitely results in the chaos of the market, giving rise to the service providers' lacking of efficient supervision to restrict their behavior. It is this illegal behavior, like sending fake messages, even dirty or commercial messages or setting traps for charges or forcing users to set combo without considering their real needs or desires, will spread wildly and unexpectedly. According to a recent study, more than 44000 cases of complaints towards the mobile communications are handled in 2009, the main problems of which are focused on SMS.

Illegal behaviors weigh the most in the reasons causing chaos in the markets. As to service providers, although it can bring about lots of benefits to behave illegally, it is, on the other hand, an indication of uncharitable punishment. As to mobile operators, to turn a permissive face toward such illegal behavior can surely lead them to enjoy certain kinds of benefits, nevertheless, negative external effects will come into being at the same time, resulting in the loss of some users in the long run. Focusing on the analysis of the two benefits sharers, that is mobile operator and service provider, of the mobile value-added markets, this article will set up a game theory model, study on the result of Nash Equilibrium of mixed strategies, and discuss administration and supervision police towards service providers based on the result of game theory.

The problem has been discussed in some papers. Zhou Jing [1] introduced that the operation mode of mobile value-added service from the aspects of planning and implementation, technical support and network, user requirements and filtering, reasonable commercial and sharing, and discussed some potential mobile value-added 
services and the effect of mobile phone on mobile valueadded services from a different point of view, which gives us a generalization of mobile value-added service. Ferdinand Jaspers [2], noticed the problem of virtual operators in mobile telecommunication, and his aim is to improve our understanding of the entry of virtual operators in general, and specifically by explaining why and how virtual operators enter the mobile market and the impact they have on competition in the mobile market. Ji Jianan [3] mainly focused on the supervision strategy for service providers in the mobile value-added market. However, the penalty for the service provider's illegal behaviors is set to be a constant in the research, which differs from the fact that the penalty is positively correlated with the benefits gained by service providers' illegal behaviors. So the outcome can't meet the fact. Tao Li [4] set up two practical game models, analyzed solutions under counterbalanced game unbalanced game between telecom runners, and put forward some suggestions for policy-making for the inter-linkage and cooperation of China's telecom industry according to correlative WTO rules. Moreover, Zhang Xinrui [5] came up with the value-added equilibrium model for complicated supply chain network by analyzing the competition game aiming at maximize the benefits of single supply chain network, which demonstrated a good use of game theory model. He really set up a perfect model under the circumstance of asymmetric cost information, and gave some further related economic explanation, which changed the current focus of competition games between the upstream and downstream companies around the core company in the single supply chain network. Dimitris Katsianis [6], presents the technoeconomic evaluation of a third generation rollout scenario followed by the identification of the market conditions for two operators in a simple game theory model, whose considered scenarios reflect the point of view of both dominant operators and new entrants. Anthony Di Benedetto[7], who pointed out that Game theory may be used to gain insight into inter-firm competition and the marketing decision-making process, aimed at the reader unfamiliar or only vaguely familiar with game theory and begins with a review of game theory terminology useful to marketing applications, where his attention then focuses on the meaning of rational behavior in less-than-perfect conditions, which is a critical issue in the application of game theory to practical business situations. Song Mei [8], in his paper, came up with a distributed Hierarchical Game (HG) theoretic framework over multi-user cooperative communication networks to stimulate cooperation and improve the network performance. Moreover, when Wang Jie [9] analyzed the issue of the determination of optimal project duration and its control, he mentioned that when the owner use the reward or the punishment to incent the contractor to reduce the project duration, the owner and the contractor will become the participants of the decision-making game and the question of incentive optimization will be resolved as a hierarchical game with the perfect information.

In detail, in this research we will analyze the behavior of two benefits shares in the mobile value-added market, which are the mobile operators and service providers respectively, with model of game theory to be established and Nash Equilibrium to be studied on. Finally, suggestions towards the supervision strategies for service providers will be given based on the analysis result.

\section{GAME MODEL OF MOBILE OPERAOTRS AND SERVICE PROVIDERS}

\section{A. Model Assumption}

- Suppose there is only one mobile operator and one service provider who participate in the game and both sides know about the structure of the game and their own payment functions.

- The mobile operator and service provider who participate in the game are non-cooperative and rational enough, aiming at pursuing to maximize their personal profits.

- The mobile operator has the responsibility to supervise the behavior of the service provider on the behalf of his own benefits, in a result, the two choices for the mobile operator are either to be the supervisor or not. As for the service provider, he can gain more profits by violating regulations and rules, which leading them to the two strategic choices of either obeying the rules or violating the rules.

- For more further assumption, when service provider chooses to violate the rules, due to the reasons such as techniques and professional virtues, two situations will be presented if mobile operators chooses to supervise: one is that the service provider will be punished when the illegal behavior is found, nevertheless, the other is that although the supervision of the mobile operator is carried out, illegal behavior of service providers is not found. Moreover, if the mobile operator didn't supervise on the service provider's actions, users may inform against the illegal behavior or no one knows the illegal behavior. If users inform against the illegal behavior, the mobile operators will absolutely be punished, losing part of their users due to insufficient administration and supervision.

\section{- Model Parameter:}

$p$ : Benefits for the service provider brought about by violating regulations and rules. When the behavior is legal, it will be set to 0 .

e : Inspection cost for the mobile operator, including all costs during the inspecting process.

$f$ : Proportion of profits gained by the mobile operator from the service provider, assuming the mobile operator charge for the service provider based on the amount of service.

$q$ : Proportion of penalty that the service provider ought to pay to the mobile operator, once they are found to behave illegally.

$k$ : Penalties for the mobile operator when they are accused by users of insufficient supervision and administration. 


\section{B. Model Analysis}

As is shown in Table 1, the payment matrix for different strategic choices of the service provider and the mobile operator can be established, based on all the assumptions above.

TABLE 1 .

GAME MATRIX ON SUPERVISION PROBLEM

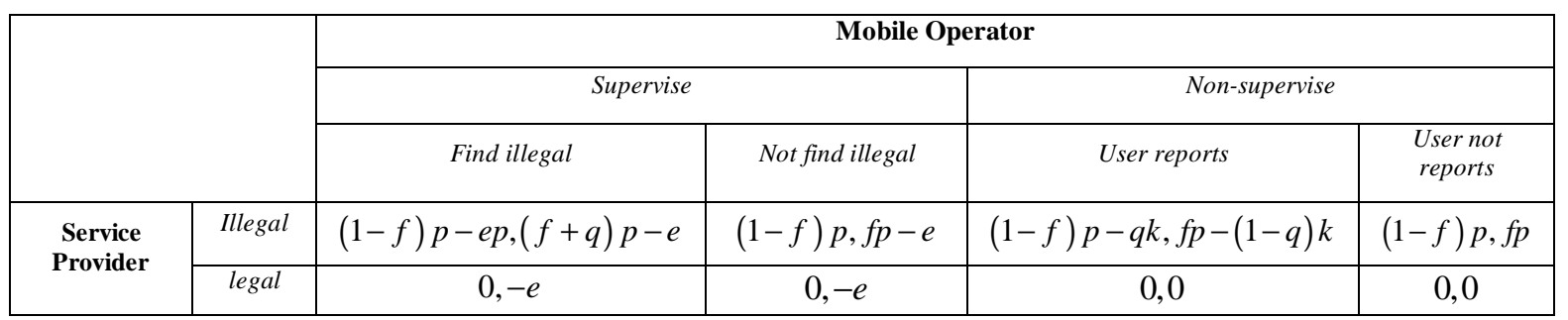

In the table above,

I When service providers violate rules, if mobile operators conduct inspection and find illegal behavior, then the benefits for service providers will be illegal income subtracting the part that submit to mobile operators and fines that punish their illegal behaviors. The stronger the inspection intensity is, which means the higher the cost of inspection is, then the more illegal activities will be found, which accounts for the fact that the amounts of fines is proportional to the inspection costs. At this time, mobile operators' benefits will come from the part that service providers carrying out illegal behaviors submit to them and the fines to punish service providers subtracting the costs of inspection.

I When service providers violate rules, if mobile operators inspect on them but no illegal activities are found, then service providers' benefits will be the illegal income subtracting the part submitted to mobile operators; while mobile operators will benefit from the part that service providers submit to them with the inspection costs subtracted. But we should not neglect that users are likely to report for the illegal behavior, so the fines of punishment for both mobile operators and service providers should also be taken into consideration.

I When service providers violate rules, if mobile operators don't inspect, but users report for their illegal behavior, then service providers will benefit from illegal income subtracting the part submitted to mobile operators and fines due to users' report, where mobile operators will benefit from the part that service providers submit to them and the fines that punish the service providers reported subtracting the fines of its own.

I When service providers violate rules, if mobile operators don't inspect and users don't report, then the benefits for service providers will be the illegal income with the part that is submitted to the mobile operators subtracted; while the benefits for mobile operators will be the part that service providers submit to them.

I When service providers do not violate rules, they don't gain benefits actually, and mobile operators will gain nothing from it. If the mobile operators perform inspection, they will definitely pay for the cost.

In order to further approach the fact, suppose that the mix strategy for the mobile operator is $\sigma_{m}=(m, 1-m)(m$ means the probability for the mobile operator's supervision, and $1-m$ means that of nonsupervision); The mix strategy for the service provider is $\sigma_{\mathrm{s}}=(\mathrm{n}, 1-\mathrm{n}) \quad(\mathrm{n}$ means the probability for the service provider to violate rules, whereas no violation is $1-n)$; The probability that the illegal activities of the service provider are found when the mobile operator supervise is $\alpha ; \beta$ represents the probability that the mobile operator don't supervise while users inform against it, and clearly $1-\beta$ represents no supervision and no informs.

When $\mathrm{n}, \alpha, \beta$ are given, the expected utility function for the mobile operator is as following:

$$
\begin{aligned}
& \mathrm{m}\left\{\begin{array}{l}
\alpha[\mathrm{n}(\mathrm{fp}+\mathrm{qe}-\mathrm{e})+(1-\mathrm{n})(-\mathrm{e})]+ \\
(1-\alpha)[\mathrm{n}(\mathrm{fp}-\mathrm{e})+(1-\mathrm{q})(-\beta \mathrm{k})+(1-\mathrm{n})(-\mathrm{e})]
\end{array}\right\} \\
& +(1-\mathrm{m})\left\{\begin{array}{l}
\beta[\mathrm{n}(\mathrm{fp}-\mathrm{k}+\mathrm{qk})+(1-\mathrm{m}) * 0]+(1-\beta) \\
{[\mathrm{npf}+(1-\mathrm{n}) * 0]}
\end{array}\right\}
\end{aligned}
$$

With differentiating the above function, we can obtain the first order condition for the mobile operator's maximum benefits:

$$
\mathrm{n} *=\mathrm{e} /[\mathrm{eq}+\beta \mathrm{k}(1-\mathrm{q})]
$$

That is to say, if the probability for the service provider violating rules is less than $\mathrm{e} /[\mathrm{eq}+\beta \mathrm{k}(1-\mathrm{q})]$, the best choice for the mobile operator is not to be the supervisor. Accordingly, if the probability is more than $\mathrm{e} /[\mathrm{eq}+\beta \mathrm{k}(1-\mathrm{q})]$, the best choice will change to be the supervisor.

When $\mathrm{m}, \alpha, \beta$ are given, the expected utility function for service providers is as following: 


$$
\begin{aligned}
& \mathrm{n}\left\{\begin{array}{l}
\mathrm{m}[\alpha(\mathrm{p}-\mathrm{pf}-\mathrm{qe})+(1-\alpha)(\mathrm{p}-\mathrm{pf}-\beta \mathrm{qk})] \\
+(1-\mathrm{m})[\beta(\mathrm{p}-\mathrm{pf}-\mathrm{qk})+(1-\beta)(\mathrm{p}-\mathrm{pf})]
\end{array}\right\} \\
& +(1-\mathrm{n})\left\{\begin{array}{l}
\mathrm{m}[\alpha * 0+(1-\alpha) * 0] \\
+(1-\mathrm{m})[\beta * 0+(1-\beta) * 0]
\end{array}\right\}
\end{aligned}
$$

With differentiating the above function, we can obtain the first order condition for the service provider's maximum benefits:

$$
\mathrm{m}^{*}=[\mathrm{p}(1-\mathrm{f})-\beta \mathrm{qk}] / \alpha \mathrm{q}(\mathrm{e}-\beta \mathrm{k})
$$

That is to say, if the probability of the mobile operator's choosing to inspect is less than $[\mathrm{p}(1-\mathrm{f})-\beta \mathrm{qk}] / \alpha \mathrm{q}(\mathrm{e}-\beta \mathrm{k})$, the best choice for the service provider is to behave illegally; if the probability is more than $[\mathrm{p}(1-\mathrm{f})-\beta \mathrm{qk}] / \alpha \mathrm{q}(\mathrm{e}-\beta \mathrm{k})$, the best choice will change to behave legally.

In a word, the Nash Equilibrium of the mix strategy is: $\mathrm{n}^{*}=\mathrm{e} /[\mathrm{eq}+\beta \mathrm{k}(1-\mathrm{q})], \mathrm{m}^{*}=[\mathrm{p}(1-\mathrm{f})-\beta \mathrm{qk}] / \alpha \mathrm{q}(\mathrm{e}-\beta \mathrm{k})$. Namely, the mobile operator chooses to inspect by the probability of $[\mathrm{p}(1-\mathrm{f})-\beta \mathrm{qk}] / \alpha \mathrm{q}(\mathrm{e}-\beta \mathrm{k})$, meantime, the service provider chooses to violate rules by the probability of $\mathrm{e} /[\mathrm{eq}+\beta \mathrm{k}(1-\mathrm{q})]$ Another explanation stated that there are large numbers of service providers in the market, where a proportion of $e /[e q+\beta k(1-q)]$ of them will behave illegally and $1-\mathrm{e} /[\mathrm{eq}+\beta \mathrm{k}(1-\mathrm{q})]$ of them will behave properly. Mobile operators will inspect on service providers with a proportion of $[\mathrm{p}(1-\mathrm{f})-\beta \mathrm{qk}] / \alpha \mathrm{q}(\mathrm{e}-\beta \mathrm{k})$.

\section{Modeling Result Analysis}

The dual role of both supervisor and benefit sharer played by the mobile operator makes it different from the common game about supervision. We can draw the following conclusion based on the game stated above:

As for the service provider, if the costs of the mobile operator's supervision ( $\mathrm{e}$ ) increase, the probability for the service provider to violate rules represented by $\mathrm{e} /[\mathrm{eq}+\beta \mathrm{k}(1-\mathrm{q})]$ will be increased accordingly, holding that the mobile operator will be less willingly to act as the supervisor and the service provider may feel free to get the illegal gain. If the mobile operator increases the penalties ( $q$ ) for the service provider when he is found to go out of the line, the probability for the service provider to violate rules will be decreased because the illegal gain may not match the penalty. Once the penalty $(k)$ for the mobile operator's insufficient inspection increasing, the probability of the service provider's going out of lines will decrease, since the mobile operator will be more active to inspect on the service provider. If the probability of users' report increases, the probability for the service provider to violate rules will decrease. So a conclusion can be drawn that it is an important way to set up a good feedback mechanism for users.
As for the mobile operator, the probability for them to choose to inspect on service providers $[\mathrm{p}(1-\mathrm{f})-\beta \mathrm{qk}] / \alpha \mathrm{q}(\mathrm{e}-\beta \mathrm{k})$, will be influenced by kinds of factors. When the proportion of illegal gains shared by the mobile operators ( $f$ ) increases, the mobile operators will probably indulge the service providers' to behave improperly out of their own benefits. The higher inspecting ability ( $\alpha$ ) that the mobile operator owns, the smaller probability for him to choose to supervise, since it is rather clear for the service provider that once he was inspected, his illegal behavior will be easily found, which will lead him to decrease the probability of violating rules. When the penalties to punish mobile operators $(k)$ increase, the probability for them to carry out inspection will be increased. Likewise, when the penalties (q) for the service provider's illegal behavior increase, he will likely decrease his illegal behavior for fear of losing more wealth, accordingly, the mobile operator will reduce his chances for inspection, after all, costs should be well considered during the inspection process. Moreover, if the probability for users to report $(\beta)$ increases, then mobile operators will increase the probability to supervise.

\section{FURTHER ANALYSIS}

All of the above is to analyze the game strategy between mobile operators and service providers from the static aspect while we need to supervise on service providers. It can clearly and essentially reflect the benefits between the two participants and the impact that different factors play on the two's optimal decision. However in fact, decision making process or even the strategy adjustment process is a dynamic gaming process. Namely, this is a multi-stage decision process.

Firstly, service providers decide on how large scale the offence is, where they correspondingly gain some illegal income and take some out for mobile operators; secondly, it is the mobile operators that decide whether to keep a check on the service providers, and the extent of investigation. Here mobile operators should also take it into account that users may report their rule violation behavior, which will definitely lead to their being punished. As it should be, the common aim for both of the two participants is to obtain the maximum benefits for themselves. After mobile operators make their decisions, service providers will have to consider the effect that this decision is going to play on their own benefits, and then adjust their strategy in order to maximize their benefits; similarly, when service providers launch their strategies, mobile operators will also adjust their strategy to meet their maximum benefits. Things go over and over again, until it reaches the final balance, where both mobile operators and service providers treat it as the optimal scheme. Mobile operators and service providers will maintain this balance in the future, if the impact factors do not make changes.

Here we will analyze this problem with the help of Stackelberg game theory [10-18], proposed by Von Stackelberg in 1952, whose characteristics are:

I More persons who are relatively independent will participate in the decision process, where 
they have their own controllable decision variables.

I Generally, one or several decision makers' decisions will influence other decision makers' benefits.

I The decision making process acts as the structure of Stackelberg theory, that is, different decision makers are at different decision making levels respectively, while decision makers at different levels own different powers. Generally, the ones at high decision making levels have greater powers, when they can control the subordinates based on their targeted strategy. Moreover, it will also exert an influence on the superiors' decision making process by the time subordinates make their decisions. In this way, the principle and subordinate relationship between superiors and subordinates is established, which reflects the mutual restraint relationship of each other.

I The final decision, made by all decision makers together, should be an optimal decision that each decision maker is satisfied with. This decision can lead the decision makers at the highest level to reach their maximum benefits, and meanwhile, the benefit of the constraint subordinates will also reach the maximum.

The model of the two-layered Stackelberg decision making problem is shown as follows:

$$
\begin{aligned}
& \max _{x} f_{0}\left(x, y_{1}, y_{2}, L, y_{p}\right) \\
& \text { s.t. }\left(x, y_{1}, y_{2}, L, y_{p}\right) \in \Omega_{0} \\
& \max _{y} f_{i}\left(x, y_{1}, y_{2}, L, y_{p}\right) \\
& \text { s.t. }\left(x, y_{1}, y_{2}, L, y_{p}\right) \in \Omega_{i}
\end{aligned}
$$

Where $x \in R^{n_{0}}$ represents the decision variable of the upper decision makers and $y_{i} \in R^{n_{i}}(i=1,2, L \quad p)$ represents the decision variables of the $i^{\text {th }}$ lower decision makers. $f_{0}: R^{n} \rightarrow R\left(n=\sum_{i=0}^{p} n_{i}\right)$ is the objective function for the upper decision makers, while $f_{i}: R^{n_{0}+n_{i}} \rightarrow R$ is the objective function of the $i^{\text {th }}$ lower decision makers. Moreover, $\Omega_{0}$ represents the constraint set for upper decision makers and $\Omega_{\mathrm{i}}$ represents the $\mathrm{i}^{\text {th }}$ lower decision makers' constraint set. $p$ stands for the number of the lower decision makers.

Compared with the previous model, here we do not use the probability that mobile operators choose to supervise on the service providers, but instead, the inspecting cost $X$ will serve as the variable to represent the extent of inspection, where $X=0$ represent that mobile operators will not keep an eye on the service providers. The bigger the value of $X$ is, then the more intensive effort mobile operators provide. At the same time, if service providers' illegal behaviors are found, then more illegal behaviors found lead to more strengthened inspection extent.

$$
\begin{gathered}
\max _{x} \text { fy }-(1-\alpha q) \mathrm{x}-\beta(1-\mathrm{q}) \mathrm{k} \\
\text { s.t. } \mathrm{x} \leq \mathrm{k}, \mathrm{x} \geq 0 \\
\max _{\mathrm{y}}(1-\mathrm{f}) \mathrm{y}-\alpha \mathrm{qx}-\beta \mathrm{qk} \\
\text { s.t. } \mathrm{y} \geq 0
\end{gathered}
$$

In this model, the statement (9) is the total revenue for mobile operators, including the benefits obtained from inspecting service providers' illegal behaviors, the fines of service providers to violate rules during the inspection process, and the fines submitted by service providers when they are reported for behaving illegally, where the inspection costs and the fines for their being reported by users should be subtracted. Here the probability for the mobile operators to find out the illegal behavior of service providers is set as $\theta$, and the probability for their being reported is $\gamma$. The constraint condition is that the inspection costs should be lower than the fines when they are reported, otherwise, out of the consideration of mobile operators self-interest, they will probably not be motivated to inspect. Statement (11) is the total revenue for service providers, including the benefits obtained by violating rules, and also subtracting a part that submitted to the mobile operators and fines for being found violating rules during the inspection process and when being reported by users.

In this model, when each parameter is given a certain value, we can easily work out its solution, furthermore, the optimal strategies for both the mobile operators and service providers will come up respectively.

\section{SUGGESTIONS ON SUPERVISION STRATEGY}

A. Strengthen Government's Supervision, and Further Improve the Data Management Platform

In order to keep the mobile value-added services' healthy development, we should give full consideration to the problems that have already existed during the mobile operation process, and try to avoid new management problems coming out. Based on the game stated above, the mobile operator chooses to supervise by the probability of $[\mathrm{p}(1-\mathrm{f})-\beta \mathrm{qk}] / \alpha \mathrm{q}(\mathrm{e}-\beta \mathrm{k})$, where $\mathrm{k}$ represents the proportion of profits shared by the mobile operator from the illegal gain of the service provider. Here we can conclude that the more benefits the mobile operator owns, that is the larger $\mathrm{k}$ is, the less impetus he has to supervise, which will give rise to larger probability for the service provider to violate rules. Because the strategic choice of the mobile operator will be influenced by potential incomes sometimes, it is necessary to let a third party, such as government, to control the proportion of benefits 
shared or put some pressure on mobile operators in order to urge them fulfill their obligation as supervisors. What's more, mechanisms like periodic inspection or even aperiodic inspection can be provided in order to guarantee the inspection density.

Furthermore, the supervision strategy cannot be decided completely by the mobile operator. Decisions made only by the mobile operator will definitely impair the supervising process, which makes the supervision strategy meaningless. Just for this purpose, mobile operators in China have all set up some service management platforms, which have the strict and unified interface and standard management. The service management for service providers is about to becoming more electronic, where people managers of each department can communicate electronically without depending on the previously paper-based or oral-based way of communication any more. This kind of platforms really increases the work efficiency and evades the annoying advertisements and harassed SMS. Consequently, in order to maintain a sound trend in the mobile value-added market, an immediate necessity is to further perfect the data management platform.

\section{B. Establish a Comprehensive User Feedback $M$ echanism and Service Provider C redit System}

From the above game model we can obtain that the common aspiration for both the service provider and the mobile operator may be obvious. That is, the service provider breaks rules, but the mobile operator doesn't care and discharge the obligation as supervisors, while users won't inform against this. Although both the two sides will benefit from the maximum degree under such case, it is the most unexpected situation for users and also the mobile value-added markets. Since the service provider violates rules in such a probability as $\mathrm{e} /[\mathrm{eq}+\beta \mathrm{k}(1-\mathrm{q})]$, it seems rather important to establish a comprehensive feedback mechanism, that is, to increase the value of $\beta$.

To establish a public and credible user feedback platform is suggested, examples like to set up a complaint platform for users with a stimulating policy. Usually it is an important method for solving the supervision issue to give some bonus to the users who offer some valuable information in the supervision process. One point should be mentioned that, platform like this should be as simple as possible, with lower costs for users' supervision, which means it won't take much time of users. Otherwise users would not like to inform against it and the illegal behavior will be connived.

Furthermore, a credit system for service providers can be considered to set up. Service providers' illegal behavior is recorded in detail during a fixed period of time, which will be converted into different point values based on the level of severity. When the point values reach a certain threshold, the punishment measure will be launched, like to have their service paused; decrease their proportion of profit sharing; or even cancelled the collaboration. Only in this way can the supervision process become more powerful.

\section{Emphasize on Cooperative $M$ anagement and Enhance Partnerships M aintenance}

In connection with the current situation of mobile data service in China, we should not only keep an eye on either of mobile operators or service providers respectively, but also should pay more attention on the cooperative management of both sides. That is to say, they two ought to be targeted at improving their joint enterprise competition, instead of only take their selfinterest into consideration. Such kind of corporation can not only consist of the transaction processing affairs, but also deepen into the strategic analyzing aspects, including communicating the tendency for the industry's development, market present situation, customers' requirements, development plans, and even promotion strategies. By fully understanding both of their strategic intent and periodic planning, the two sides can follow the principle of separation of functions, coordination and mutual check, trying to reduce unexpected conflicts and barriers to do all possible to maximize both of their benefits.

\section{CONCLUSION}

In this article the problem of the disordered mobile value-added market is analyzed and the decision making of the mobile operator and the service provider based on game theory. The Nash Equilibrium is found out and also the influence that each parameter played on the equilibrium result is discussed. As a result, we draw the conclusion that in order to establish and maintain a favorable mobile value-added market, a credible third party and a well-established user feedback mechanism are probably needed.

\section{REFERENCES}

[1] Zhou Jing, "Development and operation mode of mobile value-added services", Telecommunications Network Technology, $3^{\text {rd }}$ issue, 2003 (in Chinese).

[2] Ferdinand Jaspers ${ }^{\mathrm{a}}$, Willem Hulsink ${ }^{\mathrm{b}}$ and Jules Theeuwes ${ }^{\mathrm{c}}$, "Entry and Innovation in Maturing Markets: Virtual Operators in Mobile Telecommunications", Technology Analysis \& Strategic Management, Vol19, $2^{\text {nd }}$ issue, March 2007 , pages 205 - 225

[3] Ji Jianan, "Research on Supervision Strategies in China Mobile Value-added Market Based on Game Theory", Computer Engineering and Application, 2007 (in Chinese).

[4] Tao Li, "An analysis of the feasibility of the inter-linkage and cooperation of China's telecom industry under the WTO rules: from the angle of the game theory", J ournal of Chongaing University of Post and Telecommunications (Social Sciences Edition), $5^{\text {th }}$ issue, 2005, (in Chinese).

[5] Zhang Xinrui, "Research on value-added equilibrium of the complex supply chain networks", J ournal of Business E conomics, $7^{\text {th }}$ issue, 2007, (in Chinese).

[6] Dimitris Katsianis, "A game theory modeling approach for 3G operators", NETNOMICS, Vol. 8, No. 1. (1 October 2007), pp. 71-90

[7] Anthony Di Benedetto, "Modeling Rationality in Marketing Decision Making with Game Theory", J ournal of the Academy of Marketing Science, Vol. 15, No. 4, pp. 22-32, Winter 1987

[8] Song $\mathrm{Mei}^{\mathrm{a}}$, Teng Yinglei ${ }^{\mathrm{b}}$, Niu Fang ${ }^{\mathrm{c}}$, Zhang Yong ${ }^{\mathrm{d}}$, Wang $\mathrm{Li}^{\mathrm{e}}$, "Couple Subscriber Cooperative Relaying Networks for Uplink Transmission using Hierarchical Game Approach", China Communications, $2^{\text {nd }}$ issue, 2010. 
[9] Wang Jie, "The Determination of Optimal Project Duration Based on the Hierarchical Game", Journal of HeZhou U niversity, $1^{\text {st }}$ issue, 2010. (in Chinese)

[10] Sheng Zhaohan. Hierarchical Game Theory--Stackelberg Problem. Beijing, Science Press, 1998.

[11] Zhang Weiying, Game Theory and Information Economics Shang Hai: Joint Publishing in Shang Hai, People' s publishing house in Shang Hai, 1996.

[12] Shi Xiquan, Game Theory, Shang Hai: Shang Hai University of Finance and Economics Press, 2000.

[13] Liu Baoding ${ }^{\mathrm{a}}$, Zhao Ruiqing ${ }^{\mathrm{b}}$, Wang $\mathrm{Gang}^{\mathrm{c}}$, Theory and Practice of Uncertain Programming. Beijing: TsingHua University Press, 2003.

[14] Bialas, W.F ., Karvan J.Mb. On Two-level Optimization. IEEE Trans. Automatic Control, 1982, AC-26(1):211-214.

[15] Candler, Wa., Townsley, $\mathrm{R}^{\mathrm{b}}$. A Linear Two Level Programming Problem. Computer and Operational Research, 1982, 9(1):59-76.

[16] Falk, J.E. A Linear Max-min Problem. Mathematics Programming, 1976, 5:169-188.

[17] You Jin, "Bound Search Method for Multi-Objective decision making", System Engineering-Theory \& Practice, 1991.

[18] Rinnooy Kan, A.H.G., Timmer G.T. Stochastic Global Optimization Methods. M athematical Programming, 1987, 39(1):27-28.

[19] Xu Tong, "Prospect on Development of Mobile Valueadded Service and Network", Telecom Engineering Techniques and Standardization, $9^{\text {th }}$ issue, 2004, (in Chinese).
[20] Li Shan, "Global Mobile Value-added Services", World Telecommunications, $4^{\text {th }}$ issue, 2005, (in Chinese).

[21] Aumann, Robert J., Game Theory, The New Palgrave: A Dictionary of E conomics, 2, pp. 460-82.

[22] Aumann, Robert J. ${ }^{\mathrm{a}}$, and Sergiu Hart ${ }^{\mathrm{b}}$, . Handbook of Game Theory with Economic Applications, 3 v., Elsevier. Table of Contents and "Review Article".

[23] McMillan, J.. Games, Strategies, and Managers: How $M$ anagers $C$ an $U$ se $G$ ame Theory to $M$ ake Better Business Decisions. USA, Oxford University Press.

[24] Rasmusen, Eric, Games and Information: An Introduction to Game Theory (4th ed.), Wiley-Blackwell.

Di Zhao was born in Shan Dong province, China, in 1990, and now is a year 3 student in Beijing University of Posts and Telecommunications, Beijing, China, majoring in Telecommunication Engineering with Management.

Chuanliang J ia was born in Shan Dong province, China, in 1979. He received Bachelor of Science and Master of Science degree from Shan Dong University in Shandong Province in the year of 2000 and 2003, and received Doctor of Management from University of Science and Technology of China in An Hui province in 2006.

He has been working in Central University of Finance and Economics in Beijing China, since 2006. Till now, he has been promoted as the vice professor and served as the dean in department of management of science. His current research interest is decision making theory. 